\title{
Cancro bacteriano da videira: etiologia, epidemiologia e medidas de controle
}

\author{
Bacterial canker of grapevine: etiology, epidemiology and control strategies
}

\author{
Ana Rosa Peixoto Nascimento ${ }^{1}$ Rosa de Lima Ramos Mariano ${ }^{2}$
}

\section{- REVISÃO BIBLIOGRÁFICA -}

\section{RESUMO}

No início de 1998, o cancro bacteriano da videira, causado pela bactéria Xanthomonas campestris pv. viticola, foi detectado pela primeira vez, no Brasil, em parreirais do Submédio São Francisco, onde a doença vem ocasionando prejuízos nas cultivares suscetíveis Red Globe, Itália, Festival, Brasil, Piratininga, Patrícia, Benitaka e Catalunha. Os sintomas, nas folhas, surgem como pontos necróticos (1 a $2 \mathrm{~mm}$ de diâmetro) com ou sem halos amarelados, algumas vezes coalescendo e causando a morte de extensas áreas do limbo foliar. Nas nervuras e pecíolos, nos ramos e ráquis dos frutos, formam-se manchas escuras alongadas que evoluem para fissuras longitudinais de coloração negra conhecidas como cancros. Descoloração vascular é também observada. As bagas são desuniformes em tamanho e cor podendo apresentar lesões necróticas. A disseminação do patógeno ocorre através de material propagativo infectado, material de colheita (contentores, tesouras de poda e raleio, luvas), tratos culturais (desbrota, poda, raleio de bagas, colheita), ventos e chuvas. Apesar da região apresentar um curto período chuvoso, a disseminação da bactéria é mais eficiente durante essa época. Em condições de umidade e temperatura elevadas, o patógeno sobrevive em restos de cultura. Para o controle da doença, recomenda-se o uso de material propagativo sadio, inspeção no campo, poda drástica de órgãos infectados, eliminação de plantas severamente infectadas, condução da época de poda de produção, desinfestação de veículos, de equipamentos e de materiais para poda, utilização de fungicidas protetores cúpricos $e$ tiocarbamatos, e utilização de quebra-ventos para reduzir a disseminação do patógeno.

Palavras-chave: cancro bacteriano, Vitis vinifera, Xanthomonas campestris $p v$. viticola.

\section{ABSTRACT}

In the begining of 1998, bacterial canker of grapevine, caused by the bacterium Xanthomonas campestris pv. viticola, was detected for the first time in Brazil in vineyards of the "Submédio São Francisco". Losses in susceptible cultivars such as Red Globe, Italy, Festival, Brazil, Piratininga, Patricia, Benitaka and Catalunha were observed. In infected plants, the symptoms in leaves appear as necrotics points (1$2 \mathrm{~mm}$ of diameter) with or without yellow halos which, sometimes coalesced and causing the death of extensive leaf areas. On the leaf veins and petioles, stems and rachis of the grape clusters long dark spots are formed which progress to longitudinal fissures - the cankers. Vascular discoloration is also observed. The berries are irregular in size and color and may present necrotic lesions. The dissemination of the pathogen occurs through infected propagative material, harvesting material (containers, pruning shears and gloves), cultural practices (removal of buds, pruning, removal of berries in clusters, harvest), wind and rain. Despite the short rain season in this region, the dissemination of the bacterium is more efficient during this period. High humidity and temperature permit the survival of the pathogen in crop residues. Disease control can be achieved by using healthy propagative material, field inspection, drastic pruning on infected plants, roguing, management of the time of production pruning, disinfection of vehicles, equipments and pruning materials, use of copper and thiocarbamats as protecting fungicides and windbreaks to reduce the pathogen dissemination.

Key words: bacterial canker, Vitis vinifera, Xanthomonas campestris pv. viticola.

\section{INTRODUÇÃO}

O cultivo da videira (Vitis spp.) pode ser feito, praticamente, em todo o território nacional. Além dos estados do Rio Grande do Sul, Santa Catarina, Paraná, São Paulo, Minas Gerais, Bahia e Pernambuco onde a cultura já está estabelecida, a viticultura se

${ }^{1}$ Engenheiro Agrônomo, MSc., Fitossanidade, Professor DTCS/UNEB, Avenida Edgard Chastnet s/n, 48900-000, São Geraldo, Juazeiro, BA. Aluna do curso de Doutorado em Fitopatologia/Programa de Pós-graduação em Fitossanidade/DEPA/UFRPE Dois Irmãos, 52171-000, Recife, PE. Bolsista PICDT/CAPES. E-mail: anarpeixoto@uol.com.br. Autor para correspondência.

${ }^{2}$ Engenheiro Agrônomo, PhD., Fitopatologia, Professor do Programa de Pós-graduação em Fitossanidade/DEPA/UFRPE. Bolsista CNPq. E-mail: rmariano@truenet.com.br 
expandiu para outras regiões no decorrer dos últimos anos (KUHN et al., 1986).

O polo de irrigação do semi-árido brasileiro possui, atualmente, cerca de 4.500 hectares de videira, dos quais aproximadamente 4.000 estão em fase produtiva. O Submédio São Francisco é o principal centro produtor e exportador de uvas de mesa do Brasil, onde sobressaem os municípios de Santa Maria da Boa Vista e Petrolina, no Estado de Pernambuco, com $54 \%$ da área cultivada, seguidos dos municípios de Juazeiro, Casa Nova, Curaçá e Sento Sé, no Estado da Bahia, onde a videira tem uma grande importância sócioeconômica pelo grande número de empregos gerados. A área plantada com essa cultura tem se expandido significativamente, nos últimos anos, nessa região (SILVA \& CORREIA, 2000). A intensificação do cultivo de videira, o plantio de variedades suscetíveis, além das condições climáticas prevalentes no Submédio São Francisco têm propiciado o surgimento de problemas fitossanitários, afetando diretamente a produção e a produtividade (TAVARES, 1995). Devese considerar ainda que a aquisição de mudas sem certificação tem contribuído para a introdução de doenças nesse pólo agrícola (TAVARES \& MENEZES, 1991).

Até o final de 1997, apenas bactérias do gênero Agrobacterium haviam sido relatadas no país, infectando videira (BERIAM et al., 1991; LACERDA et al., 1991; OLIVEIRA et al., 1994). Entretanto, no início de 1998, foi detectado, pela primeira vez no Brasil o cancro bacteriano da videira em parreirais do Submédio São Francisco, onde a doença vem causando prejuízos em cultivares suscetíveis (MALAVOLTA et al., 1999). O agente causal da doença é a bactéria Xanthomonas campestris pv. viticola (Nayudu) Dye, considerada como praga Quarentenária A2 nos Estados de BA, PE e PI, de acordo com a Lei no. 9.712 de 20 de novembro de 1998. Inicialmente, a enfermidade foi observada em plantios novos, com 2 a 3 anos de idade após a enxertia, com incidência de até $100 \%$ em plantas da cv. Red Globe e em cultivares de uva sem sementes. Sintomas da doença também foram observados em plantas das cvs. Itália, Festival, Brasil, Piratininga, Patrícia, Benitaka, Ribier e Catalunha, com incidência bastante variável, principalmente, nas cvs. Itália e Benitaka, que mostraram, uma certa tolerância à doença. Sintomas semelhantes, com incidência variável, foram observados em plantios mais velhos dessas mesmas cultivares (LIMA et al., 1998).

Durante os anos de 1998 e 1999, o Laboratório de Fitopatologia da Embrapa Semi-Árido, Petrolina-PE, realizou análise para detecção de $\boldsymbol{X}$. campestris pv. viticola em 358 amostras de plantas de videira, sendo 208 da cv. Red Globe. A bactéria foi detectada em 197 (55\%) amostras, das quais 127 eram de Red Globe (LIMA et al., 2000). Com o período chuvoso ocorrido no início de 1999, observou-se a disseminação da doença para novas áreas em produção.

As informações disponíveis sobre o cancro bacteriano da videira são poucas, mesmo em nível mundial, considerando-se que, anteriormente, essa doença foi relatada apenas na Índia, onde não causou grandes prejuízos (NAYUDU, 1972).

O objetivo deste trabalho foi reunir informações sobre o cancro bacteriano da videira, disponíveis na literatura especializada, visando ao estabelecimento de estratégias para o manejo e minimização dos prejuízos causados em parreiras do submédio São Francisco.

\section{SINTOMAS}

Em plantas infectadas, os sintomas nas folhas surgem como pontos necróticos de 1 a $2 \mathrm{~mm}$ de diâmetro, com ou sem halos amarelados, algumas vezes coalescendo e causando a morte de extensas áreas do limbo foliar. Nas nervuras e pecíolos das folhas, nos ramos e ráquis dos frutos formam-se manchas escuras e alongadas, que evoluem para fissuras longitudinais de coloração negra conhecidas como cancros. As bagas são desuniformes em tamanho e cor (NAYUDU, 1972) podendo apresentar lesões necróticas. A intensidade dos sintomas causados por $X$. campestris pv. viticola varia segundo o nível de tolerância da variedade à doença e segundo as condições ambientais (LIMA, 2001).

\section{ETIOLOGIA E CICLO DAS RELAÇÕES PATÓGENO-HOSPEDEIRO}

A bactéria, agente do cancro bacteriano da videira, identificada através de testes bioquímicos, culturais, fisiológicos e de patogenicidade em videira, é $X$. campestris pv. viticola (MALAVOLTA et al., 1999). Os testes de patogenicidade foram realizados em plantas das cvs. Red Globe (LIMA et al., 1998), Piratininga e Itália (NASCIMENTO et al., 1998), nas quais foram reproduzidos os sintomas da doença, completando, assim os Postulados de Koch.

A bactéria $X$. campestris pv. viticola, anteriormente denominada de Pseudomonas viticola sp. nov. (DESAI et al., 1966) é um bastonete Gram-

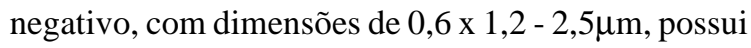
um flagelo polar e metabolismo aeróbico.

As colônias são arredondadas, brilhantes com bordos lisos e de coloração esbranquiçada, em 
meio agar-nutritivo, pois não produz xantomonadina, pigmento característico das bactérias do gênero Xanthomonas, com exceção de alguns patovares ou isolados de um mesmo patovar (BRADBURY, 1986; SWINGS et al., 1993). Não utiliza o nitrato como fonte de nitrogênio; a asparagina não é utilizada como fonte de carbono e nitrogênio, cresce bem em sais de amônio e ácido glutâmico, embora seu melhor crescimento seja em caseína hidrolisada (NAYUDU, 1972). Produz ácido a partir de glicose, manose, galactose, trealose, celobiose e frutose, mas não de dulcitol, glicerol, m-inositol, lactose, rafinose e sorbitol. Os testes de hipersensibilidade foram negativos em folhas de fumo (LIMA, 2001; MALAVOLTA et al., 1999), mas positivos em folhas de tomate cv. Santa Clara (MALAVOLTA et al., 1999). A caracterização bioquímica de vinte e dois isolados do patógeno, provenientes de parreirais de Pernambuco e Bahia, indicou tratar-se de um grupo homogêneo, mostrando também o valor diagnóstico deste conjunto de testes (reação positiva para: produção de ácidos a partir de glucose, arabinose e manose; produção de $\mathrm{H}_{2} \mathrm{~S}$; catalase; proteólise de caseína e hidrólise de gelatina, esculina e amido; e reação negativa para: redução de nitrato e oxidase). A variação observada deu-se quanto à reação de hipersensibilidade em fumo (negativa para sete isolados e fraca - após 72h. para os demais) e tolerância máxima ao $\mathrm{NaCl}$ (variou entre 1 e 5\%) (FERREIRA et al., 2000). TRINDADE \& FERREIRA (2001) visando à caracterização molecular de $\boldsymbol{X}$. campestris pv. viticola através de REP-PCR verificaram uniformidade entre os padrões de REP-PCR obtidos para cinco isolados coletados em duas épocas (1998 e 2000) em três áreas distintas na região de Petrolina-PE, e provenientes de plantas de Red Globe e Itália, permitindo a diferenciação em relação ao isolado UnB-764, de $X$. campestris pv. mangiferaeindicae.

Xanthomonas campestris pv. viticola pode ser introduzida em parreirais, nos quais a doença ainda não ocorre, veiculada em mudas ou bacelos infectados, os quais irão originar plantas doentes. Superfície de hastes e folhas com sintomas do cancro bacteriano da videira e também de folhas assintomáticas, provenientes de áreas afetadas, revelaram intensa colonização de $\boldsymbol{X}$. campestris pv. viticola. As observações feitas ao microscópio eletrônico de varredura permitiram afirmar que as células bacterianas aderem randômicamente às superfícies vegetais por meio de fixação apolar em monocamada, raramente formando agregados, e que maior frequência dessa adesão ocorre sobre nervuras e tricomas, no limbo foliar. Assim, pressupõe-se que, uma vez as bactérias atingindo um sítio favorável, sua habilidade de resistir à remoção constitui-se em vantagem seletiva, sendo responsável pelo aumento e estabilidade da população residente (ARAÚJO, 2001).

A disseminação da bactéria pode ocorrer através de restos de cultura infectados espalhados pelo pomar ou aderidos em roupas, veículos, mas principalmente em contentores, tesouras, canivetes e luvas não desinfestadas utilizadas na colheita de frutos de plantas doentes. Tratos culturais como desbrota, poda, raleio de bagas, colheita, torção de ramos antes da aplicação de Cianamida Hidrogenada, cuja finalidade é estimular e uniformizar a brotação (MASHIMA, 2000), capina, gradagem, roçagem, pulverizações e até a aplicação de herbicidas por barra favorecem a disseminação da bactéria no parreiral. A bactéria pode ser transportada por respingos de água de chuva ou irrigação, que a levam a longas distâncias (CHAND et al., 1991). A irrigação dos tipos sobrecopa, tanto a aspersão convencional como o pivô central, favorecem a distribuição da doença. Apesar do curto período chuvoso na região do Submédio São Francisco, a disseminação da bactéria ocorre mais rapidamente e a infecção pode ser mais intensa durante esse período (NASCIMENTO et al., 2000b). O vento seco não dissemina a bactéria, sendo necessário sempre a presença de água. A transmissão do cancro bacteriano dentro do pomar pode ocorrer mais rapidamente que entre pomares. Dessa forma, é importante que o viticultor esteja atento ao surgimento de sintomas da doença no parreiral, realizando inspeções periódicas que permitam a detecção de focos iniciais de infecção, retardando ou evitando a disseminação do patógeno e favorecendo o manejo da doença. Todos os agentes de ferimentos são importantes para a penetração de bactéria destacandose os tratos culturais e ventos fortes. Após a penetração, a bactéria multiplica-se rapidamente colonizando os espaços intercelulares e atingindo o sistema vascular, sendo transmitida a todos os órgãos da planta.

De acordo com CHAND \& KISHUM (1990b), fatores como temperaturas em torno de 25 a $30^{\circ} \mathrm{C}$ e alta umidade relativa do ar proporcionam condições favoráveis ao desenvolvimento do patógeno.

\section{SOBREVIVÊNCIA E GAMA DE HOSPEDEIROS}

A bactéria sobrevive de um ciclo para o outro em plantas infectadas, ou como epifítica em órgãos da parte aérea de plantas, em condições de umidade e temperaturas elevadas (ARAÚJO, 2001). 
Não sobrevive no solo, persistindo apenas em restos culturais (NASCIMENTO et al., 2000b). Em inoculações artificiais com $X$. campestris pv. viticola, observouse infecção em plantas de mangueira (Mangifera indica L.), como também relatado por CHAND \& KISHUM (1990a), cajueiro (Anacardium ocidentale L.), umbuzeiro (Spondias tuberosa Arruda), cajámanga (Spondias dulcis Forst.) e aroeira (Schinus terebenthifolius Radii) (ARAÚJO et al., 1999), bem como neem (Azadirachta indica A. Juss) (MALAVOLTA \& ALMEIDA, 2000). Na Índia, DESAI et al. (1966) também observaram que o neem, importante planta utilizada como quebra-vento e seu extrato como inseticida natural, é hospedeira desta bactéria, apresentando manchas foliares e cancros em ramos e pecíolos, sintomas semelhantes aos observados em videira. O patógeno também pode sobreviver em Phyllanthus maderaspatensis (CHAND \& KISHUN, 1990a).

LIMA \& FERREIRA (2000) e NASCIMENTO et al. (2000a) observaram que a bactéria foi também detectada em plantas de IAC $766 \mathrm{com}$ sintomas, e em plantas assintomáticas de IAC 572, utilizadas como porta-enxertos na região do Vale do São Francisco, ambas enxertadas com a cultivar suscetível Red Globe.

\section{MEDIDAS DE CONTROLE}

O cancro bacteriano é uma doença nova na cultura da videira no Brasil, tendo sido relatada apenas na Índia, onde não causou grandes prejuízos. Portanto, existem poucos dados disponíveis em literatura sobre a epidemiologia e manejo da doença. Algumas considerações são feitas, a seguir, visando o estabelecimento de estratégias para o manejo dessa enfermidade no campo.

\section{Controle cultural}

Os materiais propagativos e mudas constituem os meios mais eficientes de disseminação do cancro bacteriano, principalmente a longas distâncias. Ao adquirir mudas ou qualquer material propagativo, exigir sempre o Certificado Fitossanitário de Origem - CFO (INSTRUÇÃO NORMATIVAn ${ }^{\circ} 246$, 1998). Realizar inspeções periódicas no parreiral, se possível semanalmente, é extremamente importante para a detecção de sintomas de cancro bacteriano. A verificação da ocorrência da doença no parreiral nos estágios iniciais facilita o seu manejo. ARAÚJO (2001) produziu anticorpos policlonais que se mostraram altamente reativos contra o patógeno, podendo ser empregados no diagnóstico da doença e em programas de certificação de material propagativo. Eliminar todos os ramos infectados quando forem detectadas plantas com sintomas de cancro bacteriano. As operações de poda devem sempre ser realizadas com ferramentas desinfestadas, no período de estiagem, considerandose que as chuvas favorecem a disseminação da bactéria dentro do parreiral. Os cortes resultantes da poda ou quaisquer ferimentos na planta deverão ser pincelados com pasta cúprica. Todo material removido nas operações de poda, bem como os restos de cultura, deverão ser amontoados próximo ao foco e incinerados, evitando transportá-los. Não é recomendado juntar os materiais resultantes da poda de diversos focos de infecção em um só local para incineração (BRASIL, 1998). Similarmente, plantas severamente infectadas devem ser arrancadas, inclusive as raízes, e incineradas imediatamente no local. Nas áreas de erradicação, é aconselhável não plantar videira por um período de até seis meses, fazendo-se a desinfestação da cova com cal. O parreiral deve ser mantido sem plantas invasoras visando eliminar possíveis hospedeiros alternativos do patógeno (LIMA, 2001).

A poda de produção, cuja finalidade é assegurar a regularidade das colheitas em quantidade e qualidade, mantendo a planta em equilíbrio vegetativo (MASHIMA, 2000), deve ser programada de modo a evitar que os estádios compreendidos entre brotação e chumbinho coincidam com o período de chuvas. Podas de cultivo a partir da segunda semana de outubro possibilitam o escape da doença em áreas produtoras, na Índia (CHAND et al., 1991).

Veículos, equipamentos e materiais de poda, raleio e colheita devem ser desinfestados com amônia quaternária (Quatermon 1 litro /1000 litros de água) (LIMA, 2001).

\section{Controle químico}

Segundo ROMEIRO (1988, 1995, 2001), os fungicidas cúpricos e alguns tiocarbamatos podem atuar na proteção de plantas, em relação a fitobactérias, originando uma delgada película na superfície do filoplano, a qual atua retardando, inibindo ou bloqueando a multiplicação do patógeno no local pulverizado, devido ao efeito bacteriostático ou bactericida do produto.

A fase crítica para estabelecer estratégias para o manejo do cancro da videira é a época das chuvas, quando os parreirais devem estar protegidos. Trabalhos desenvolvidos na Índia por CHAND et al. (1994) avaliaram a eficiência de oxicloreto de cobre, sulfato de estreptomicina, tetraciclina e bacterinol 100 em mudas de videira com 85 a 100\% de infecção por X. campestris pv. viticola, em viveiro, no período 
de 1987 a 1990. Entretanto, nenhum desses produtos foi eficiente no controle da doença, provavelmente porque as mudas estavam com alto nível de infecção. No caso de viveiros, o mais recomendado é a destruição das mudas e a aquisição de novo material para enxertia, livre de doença. Em experimentos de campo, CHAND et al. (1992) observaram que aplicações de oxicloreto de cobre, seguidas por aplicações de calda bordaleza, reduziram a severidade dos sintomas do cancro bacteriano em plantas infectadas. Entretanto, essas aplicações foram menos efetivas em áreas com chuvas freqüientes.

LIMA \& MASHIMA (2000) testando o efeito de produtos químicos (Oxitetraciclina, Sulfato de cobre, Amônia quaternária, Chloranphenicol e Cobre líquido) e termoterapia (água quente $-48-50^{\circ} \mathrm{C} /$ $15 \mathrm{~min}$.) no tratamento de bacelos infectados com $\boldsymbol{X}$. campestris pv viticola verificaram sintomas da doença em pecíolos e folhas, para todos os tratamentos testados, em percentagens variáveis. Testes "in vitro" foram realizados por NASCIMENTO et al. (2000 b) que comprovaram a inibição do crescimento do patógeno em presença de alguns produtos, evidenciando-se os maiores halos de inibição quando se utilizou Sulfato de gentamicina + Oxitetraciclina; Sulfato de gentamicina + Oxitetraciclina + bioestimulante e Oxitetraciclina.

SILVA et al. (2000) obtiveram os maiores índices de inibição do patógeno, em condições de laboratório, quando testaram Sulfato de gentamicina + Oxicloreto de cobre, seguido por Íon zinco + Hidróxido de cobre e Íons zinco + Oxicloreto de cobre. No Brasil, ainda não há produtos registrados junto ao Ministério da Agricultura e do Abastecimento para o controle do cancro da videira. No entanto, produtos à base de cobre têm sido utilizados em pulverizações de plantas e em pincelamento de ferimentos no manejo da doença no Submédio São Francisco (LIMA, 2001).

\section{Outras medidas}

Antes da implantação do pomar, é recomendável cercar a propriedade para que haja controle no acesso de pessoas e veículos. A utilização de quebra-ventos é também aconselhada, com o objetivo de proteger o parreiral da disseminação de $\boldsymbol{X}$. campestris pv. viticola em respingos de água transportados pelo vento, reduzir os ferimentos nas plantas e reduzir ou evitar a entrada de pragas, como ácaros e tripes, entre outros. Os quebra-ventos, protegem a cultura a uma distância, em média, dez vezes maior que a altura da planta utilizada. Eles devem ser colocados ao lado de carreadores principais e locais de intenso tráfego de veículos. Várias espécies de plantas podem ser utilizadas como quebra-ventos, entre as quais se destacam: grevilha (Grevillea robusta), que pode atingir até $15 \mathrm{~m}$ de altura em cinco anos e não necessita de poda; capim cameron (Pennisetum purpureum), que é a espécie mais utilizada como quebra-vento na região do Submédio São Francisco, atingindo até $5 \mathrm{~m}$ de altura em 4 meses; sansão do campo (Mimosa caesalpinifolia), cujas plantas atingem até $8 \mathrm{~m}$ de altura em três anos, possuem muitos espinhos, são resistentes ao fogo, mas apresentam a desvantagem de serem hospedeiras de cochonilhas e ácaros; e ainda casuarina (Casuarina sp.), um tipo de Pinus muito utilizado no município de Mossoró-RN, mas que geralmente não se adapta a solos argilosos com pouca drenagem.

A utilização de variedades resistentes é ainda um dos métodos mais eficientes para fitobacterioses. CHAND (1992), buscando fontes de resistência em videiras a $\boldsymbol{X}$. campestris pv. viticola, testou 14 espécies de Vitis; espécies de sete gêneros pertencentes a família Vitaceae e 73 cultivares de $\boldsymbol{V}$. vinifera e $\boldsymbol{V}$. labrusca em condições de infecção natural e inoculação artificial, no período de 1988-90. Vitis vinifera comportou-se como altamente susceptível, enquanto outros gêneros de Vitaceae, dentre eles, Ampelocissus sp., Ampelopsis sp., Cissus sp. e Leea sp. e algumas espécies de Vitis como $\boldsymbol{V}$. champini, $V$. rupestris, $V$. candicans $e V$ c cinerea foram altamente resistentes. Cultivares sem sementes de $\boldsymbol{V}$. vinifera foram mais suscetíveis do que cultivares com sementes. Em relação às cultivares sem sementes, as coloridas mostraram-se mais suscetíveis do que as cultivares brancas. Recomenda-se, portanto, na instalação de novos plantios, evitar as variedades mais suscetíveis ao cancro bacteriano, como Red Globe e as sem sementes.

\section{CONSIDERAÇÕES GERAIS}

Apesar do cancro bacteriano da videira ser uma doença de ocorrência recente, no Brasil, e haver a deficiência de literatura sobre o assunto, algumas recomendações de manejo da doença podem ser feitas, baseadas no que vem sendo aplicado por viticultores no Submédio São Francisco, possibilitando uma produção satisfatória, mesmo com o patógeno instalado no pomar. Por conseguinte, recomenda-se: instalar rodolúvio na entrada das fazendas com Amônia quaternária a $0,1 \%$ ou tapete de cal; evitar o trânsito de máquinas e equipamentos entre propriedades e lotes; utilizar material vegetativo sadio; evitar irrigação sobre-copa; desinfestar contentores de colheita e ferramentas entre cada planta tratada; 
pulverizar as plantas podadas e feridas com cobre; eliminar e queimar restos de cultura e eliminar plantas daninhas do parreiral.

Tratando-se de um patógeno extremamente agressivo e recentemente instalado no Submédio São Francisco, importante produtor de uvas de mesa do Brasil, várias pesquisas são necessárias para minimizar a deficiência de informações e de conhecimento sobre X. campestris pv. viticola. Um levantamento epidemiológico para caracterizar a intensidade da doença nos municípios produtores de uva da região do Submédio São Francisco, bem como estudos de variabilidade de isolados do patógeno com relação a hospedeiros, a componentes epidemiológicos, produtos químicos e a caracterização molecular. Além disso, também seriam interessantes estudos de sobrevivência, disseminação e de preservação, testes de resistência de variedades de copa e porta-enxerto; seleção de organismos para controle biológico e testes de indução de resistência sistêmica, entre outros.

\section{REFERÊNCIAS BIBLIOGRÁFICAS}

ARAÚJO, J.S.P. Perfil epidemiológico e subsídios para o controle de Xanthomonas campestris pv. viticola (Nayudu) Dye, agente do cancro bacteriano da videira (Vitis vinifera) no Brasil. 2001. 121f. Tese (Doutorado em Fitotecnia) - Universidade Federal Rural do Rio de Janeiro.

ARAÚJO, J.S.P.; ROBBS, C.F.; MACIEL, G.F. Novos hospedeiros alternativos de Xanthomonas campestris pv. viticola no Brasil. Summa Phytopathologica, Jaboticabal, v.25, n.2, p.23, 1999.

BRADBURY, J.F. Guide to plant pathogenic bacteria. Kew : C.A.B. International, 1986. 332p.

BERIAM, L.O.S.; ROBBS, C.F.; RODRIGUES NETO, J. Galha bacteriana (Agrobacterium sp.) em videira no Estado do Rio Grande do Norte. In: REUNIÃO ANUAL DO INSTITUTO BIOLÓGICO, 4., 1991, São Paulo. Resumos... São Paulo: Instituto Biológico, 1991. np.

BRASIL. Secretaria de Defesa Agropecuária. Instrução normativa n. 233 de 7 de dez, 1998. Dá continuidade aos trabalhos de levantamento da praga Xanthomonas campestris pv. viticola na Região do Submédio São Francisco e institui normas para sua erradicação. Diário Oficial (da República Federativa do Brasil), Brasília, 30 dez 1998. Seção 1:p.89.

CHAND, R. Source of resistance to grapevine bacterial canker disease in Vitis. Indian Institute of Horticultural Research, Bangalore, v. 31, p. 83-86, 1992.

CHAND, R.; KISHUN, R. Outbreak of grapevine bacterial canker disease in India. Vitis, v.29, p.183-188, 1990 a.

CHAND, R.; KISHUN, R. Effect of temperature on the growth of grape vine bacterial pathogen. Drakshavritta Souvenir, v.73, p.5, 1990 b.
CHAND, R.; PATIL, P.B.; KISHUM, R. Efficacy of different chemicals against grapevine bacterial canker disease (Xanthomonas campestris pv. viticola). Indian Journal of Plant Protection. v.20, n.1, p.108-110, 1992.

CHAND, R.; PATIL, P.B.; KISHUM, R. Management of bacterial canker disease (Xanthomonas campestris pv. viticola) of grape vine (Vitis vinifera) by prunning. Indian Journal of Agricultural Sciences, v.61, n.3, p.220-222, 1991.

CHAND, R. et al. Copper and streptomycin resistance in Xanthomonas campestris pv. viticola. Zeitschrift fur Pflanzenkrankheiten un Pflanzenschutz. v.101, n.5, p.487-491, 1994.

DESAI, S. G. et al. A new bacterial leaf-spot and blight of Azadirachta indica A. Juss Indian Phytopath, v.19, p.322323, 1966.

FERREIRA, M.A.S.V. et al. Caracterização bioquímica de isolados de Xanthomonas campestris pv. viticola. Fitopatologia Brasileira, Brasília, v.25, Suplemento, p.459, 2000 .

INSTRUÇÃO NORMATIVA 246, 1998. Ministério da Agricultura e do Abastecimento. Disponível em: <www.dou.gov.br> Acesso em: 23 outubro 2001.

KUHN, G.B. et al. O cultivo da videira: informações básicas. 2.ed. Bento Gonçalves : EMBRAPA-CNPUV, 1986. 60p. (EMBRAPA-CNPUV. Circular Técnica, 10).

LACERDA, B.S.L. et al. Ocorrência de galha em videira incitada por Agrobacterium. Fitopatologia Brasileira, Brasília, v.16, n.2, p.47, 1991.

LIMA, M.F. Cancro bacteriano da videira, causado por Xanthomonas campestris pv. viticola. Disponível em <www.cpatsa.embrapa.br/artigos/cancro.html> Acesso em: 11 de julho 2001.

LIMA, M.F.; FERREIRA, M.A.S.V. Infecção latente em porta-enxertos de videira causada por Xanthomonas campestris pv. viticola. In: CONGRESSO PAULISTA DE Fitopatologia, 23, Campinas, SP. Programa e Resumos... Campinas : SPF, 2000. p.283.

LIMA, M.F.; MASHIMA, C. Tratamento químico e térmico de bacelos de videira infectados com Xanthomonas campestris pv. Viticola. Fitopatologia Brasileira, Brasília, v.25, Suplemento, p.324, 2000 .

LIMA, M.F.; MOREIRA, W.A.; FERREIRA, M.A.S.V. Detecção do cancro da videira causado por Xanthomonas campestris pv. viticola em 1998 e 1999. In: CONGRESSO PAULISTA DE FItopatologia, 23 Campinas, SP. Programa e Resumos... Campinas : SPF, 2000. p.284.

LIMA, M.F. et al. Ocorrência de bacteriose em videira (Vitis spp.) no Brasil. Fitopatologia Brasileira, Brasília, v.23, Suplemento, p.210, 1998.

MASHIMA; C.H. Uva sem semente. Recife : SEBRAE/PE. 2000. 51p. (Agricultura; 14).

MALAVOLTA, V.M.A.; ALMEIDA, I.M.G. Patogenicidade de Xanthomonas campestris pv. viticola em neem. Summa Phytopathologica, Jaboticabal, v.26, n.1, p.129, 2000. 
MALAVOLTA, V.M.A. et al. Ocorrência de Xanthomonas campestris pv. viticola em videira no Brasil. Summa Phytopathologica, Jaboticabal, v.25, n.3, p.262-264, 1999.

NASCIMENTO, A.R.P.; MASHIMA, C.H.; LIMA, M.F. Cancro bacteriano: nova doença da videira no submédio São Francisco. Petrolina : Embrapa Semi-Árido, 2000a. 22p. (Embrapa Semi-Árido. Circular Técnica 58).

NASCIMENTO, A.R.P. et al. Sensibilidade "in vitro" de Xanthomonas campestris pv. viticola a bactericidas e fungicidas. Fitopatologia Brasileira, Brasília, v.25, Suplemento, p.326$327,2000 b$

NASCIMENTO, A.R.P. et al. Avaliação da patogenicidade da bactéria da necrose em videiras (Vitis spp.). Fitopatologia Brasileira, Brasília, v.23, Suplemento, p.213, 1998.

NAYUDU, M.V. Pseudonomonas viticola sp. nov., incitant of a new bacterial disease of grape. Phytopathologische Zeitschrift, v.73, p.183-186, 1972.

OLIVEIRA, J.R.; ROMEIRO, R.S.; LACERDA, B.S.L. Occurrence of Agrobacterium tumefaciens biovar 3 on grapevine in Brazil. Journal of Phytopathology, Berlim, v.140, p.363366, 1994.

ROMEIRO, R. da S. Bactérias fitopatogênicas. Viçosa : UFV, 1995. 283p.

ROMEIRO, R.S. Fundamentos de bacteriologia de plantas. Viçosa : UFV, 1988. 50p.
ROMEIRO, R.S. Métodos em bacteriologia de plantas. Viçosa : UFV, 2001. 279p.

SILVA, V.A.V. et al. Ação "in vitro" de produtos químicos em relação a Xanthomonas campestris pv. viticola. Fitopatologia Brasileira, Brasília, v.25, Suplemento, p.331, 2000.

SILVA, P.C.G. da; CORREIA, R.C. Caracterização social e econômica da videira. In: LEÃO, P.C.de S.; SOARES, J.M. A viticultura no Semi-árido brasileiro. Petrolina : Embrapa Semi-Árido, 2000. 336p

SWINGS, J.; VAUTERIN, L.; KERSTER, K. The bacterium Xanthomonas. In: SWINGS, J.G.; CIVEROLO, E.L. (Ed.) Xanthomonas. London : Chapman \& Hall, 1993. p.127156 .

TAVARES, S.C.C. de H. Principais doenças das culturas de: manga, uva, acerola e banana. Petrolina : EMBRAPA. CPATSA, 1995. 1v. (Apostila do Curso de Atualização Técnica para Engenheiros Agrônomos do Banco do Brasil, Petrolina, PE, 1995).

TAVARES, S.C.C. de H.; MENEZES, M. Processo de infecção de Botryodiplodia theobromae em plantas de mangueira e videira no trópico semi-árido brasileiro. F itopatologia Brasileira, Brasília, v.16, p.55, 1991

TRINDADE, L.C.; FERREIRA, M.A. Caracterização de Xanthomonas campestris pv. viticola através de REP-PCR. Fitopatologia Brasileira, Brasília, v. 25 (Suplemento), p. 285,2001 